*Mestranda em Direito pela Universidade de Ribeirão Preto (UNAERP).

Especialista em Direito Notarial e Registral em 2015 pela Universidade de Ribeirão Preto (UNIDERP).

Especialista em Direito Processual Civil em 2013 pela Universidade de Ribeirão Preto (UNIDERP).

Graduação em Ciências Jurídicas e Sociais em 2010 pelo Instituto de Ensino Superior de Santo Ângelo (IESA).

E-mail: annaczenkner@hotmail. com

**Pós-Doutor em Direito em 2010 pela Faculdade de Direito da Universidade de Coimbra (FDUC-PT).

Doutorado em Sociologia em 2005 pela Universidade Estadual Paulista Júlio de Mesquita Filho (UNESP).

Mestrado em Sociologia em 2000 pela Universidade Estadual de Campinas (UNICAMP).

Especialista em Didática de Planejamento do Ensino Superior em 1991 pela Faculdade de Filosofia de Passos (FAFIPA).

Graduação em Direito em 1997 pela Faculdade de Direito de Franca (FADIPA).

E-mail: juvencioborges@gmail. com

\section{Acesso À Justiça Pela Atuação Profilática do Tabelião: A Mediação Extrajudicial Como Meio Alternativo De Solução De Conflitos}

\author{
Access To Justice For The Profilatic Activity Of The \\ Notary: Extrajudicial Mediation As An Alternative \\ Means Of Conflict Solution
}

Como citar: ZENKER, Anna Cristina; SILVA, Juvêncio Borges. Acesso à justiça pela atuação profilática do tabelião: a mediação extrajudicial como meio alternativo de solução de conflitos. Scientia Iuris, Londrina, v. 22, n. 3, p. 88-110, nov. 2018. DOI: 10.5433/2178-8189.2018v22n3p88. ISSN: 2178-8189.

Resumo: $\mathrm{O}$ artigo discute o direito fundamental do acesso à justiça e a necessária ressignificação do seu conteúdo, diante de uma crise institucional vivenciada pelo Poder Judiciário no Brasil. O colapso do sistema jurisdicional, que descredita o Judiciário e o deslegitima enquanto. Poder; faz nascer a imperiosa necessidade de se discutir mecanismos alternativos para a solução de controvérsias, que mitiguem o excesso de judicialização. Assim, o conceito de acesso de justiça deve ser interpretado à luz da realidade jurídica nacional, com soluções que transcendem o Poder Judiciário, tais como a mediação e a conciliação. Nesse sentido, o desenvolvimento da mediação extrajudicial, além de possível, é desejável e permitirá, em boa medida, uma ruptura com a "cultura da sentença" e o descongestionamento dos tribunais. A pesquisa se orienta pelo método analítico-dedutivo, com fulcro em livros, artigos científicos e jurisprudências para, ao final, demonstrar que a atuação preventiva e mediadora do notariado pode construir muitas soluções dialogais e impedir que muitos processos judiciais se iniciem. É, pois, a profilaxia a serviço da doença crônica denominada inefetividade e morosidade judicial.

Palavras-chave: Acesso à justiça. Meios alternativos de solução de conflitos. Mediação extrajudicial.

Abstract: The article discusses the fundamental right of access to justice and the necessary resignification of its content, in the face of an institutional crisis experienced by the Judiciary in Brazil. The collapse of the judicial system, which discredits the Judiciary and de-legitimizes it as a Power, gives rise to the urgent need to discuss alternative mechanisms for the settlement of disputes, which mitigate the excessive judicialization. Thus, 
the concept of access to justice must be interpreted in the light of national legal reality, with solutions that transcend the Judiciary, such as mediation and conciliation. In that sense, the development of extrajudicial mediation is, in addition, possible, desirable and will, to a large extent, allow a break with the "culture of sentencing" and the decongestion of the courts. The research is guided by the analytic-deductive method, with a focus on books, scientific articles and jurisprudence, in order to demonstrate that the preventive and mediating action of the notary can construct many dialogical solutions and prevent many judicial processes from beginning. It is, therefore, prophylaxis in the service of the chronic disease denominated ineffectiveness and judicial slowness.

Keywords: Access to justice. Alternative means of conflict resolution. Extrajudicial mediation. 


\title{
INTRODUÇÃO
}

É notório que as dificuldades da Jurisdição tradicional se agravaram e que sua capacidade de responder as demandas sociais está cada vez mais prejudicada. O aumento de demandas, a complexidade dos conflitos e o esgotamento do positivismo jurídico, são elementos que, interconectados, evidenciam uma crise de racionalidade e operacionalidade jurídica moderna e exigem a construção de novos saberes e procedimentos. É o que observam Bittar e Almeida (2017, p. 769):

\begin{abstract}
Liberalismo, capitalismo e individualismo são as marcas da modernidade jurídica, que se encontra desafiada em suas formas de organização por novos desafios históricos e contextuais. O que se percebe é que as promessas de igualdade, fraternidade e liberdade não foram cumpridas, e, como rescaldo desta utopia moderna, resta apenas um enorme saldo de injustiça social. Então, os estremecimentos pós-modernos encaminham a reflexão para a constatação de que está em curso um revisionismo das insuficiências da modernidade jurídica, de seus abusos e de sua obsolescência. Os tradicionais paradigmas que serviram bem ao Estado de Direito do século XIX não se encaixam mais para formar a peça articulada de que necessita o Estado Contemporâneo para a execução de políticas públicas efetivas. É nesta medida que se constata a perda de significação: da universalidade da lei, pois os atores sociais possuem características peculiares não divisáveis pela legislação abstrata; do princípio da objetividade do direito, que o torna formalmente isento de qualquer contaminação de forças políticas, quando se sabe que toda a legislação vem formulado na base de negociações políticas e partidárias; da ideia da contenção do arbítrio pela lei, fator em descrédito frente à ineficácia e à inefetividade das atitudes de combate à corrupção e às taxas elevadíssimas de impunidade [...] da garantia da existência da jurisdição como garantia de acesso a direitos, quando se sabe que, em verdade, a justiça se diferencia para ricos e pobres, entre outros fatores.
\end{abstract}

Enfim, o paradigma de um direito que estabeleceu o fetiche da lei, que se pretende isento, neutro, infenso a ideologia, como era o caso do discurso moderno positivista, não se sustenta diante da realidade e das transformações pelas quais passa a sociedade. A judicialização da política e a politização do direito são fenômenos que estão na pauta das discussões que extrapolam os limites do direito e da academia, e se manifestam até mesmo mídia televisiva, internet e redes sociais.

Diante de um quadro de reconhecidas dificuldades e precariedades das formas tracionais de jurisdição, da morosidade processual, do número agigantado de processos que tramitam nos tribunais, gerando o que ficou nominado como "congestionamento processual", faz-se necessário refletir sobre o acesso à justiça e o desafio da atividade notarial na construção de espaços alternativos de acesso à justiça e de resolução de conflitos, considerando que a recente Lei da Mediação $n^{\circ}$ 13.140/2015 (BRASIL, 2015c), e as iniciativas do Conselho Nacional de Justiça (CNJ) e dos Tribunais de Justiça destacam e estimulam a mediação e a negociação como uma nova possibilidade de atuação desse setor.

É sob esse viés que buscamos debater a possibilidade de a atividade notarial desempenhar um papel mais atuante na resolução de conflitos, mediante a institucionalização de espaços de negociação e mediação, aproveitando a sua estrutura física e se valendo das funções já creditadas 
e amplamente enraizadas na tradição jurídica nacional.

Ao se apostar em novos mecanismos alternativos de resolução de conflitos, como a mediação e a negociação, não se está apenas enfrentando um problema estatístico de celeridade e quantidade de processos, mas promovendo um deslocamento qualificativo de compreensão do litígio, de sua substância. Não se trata de substituir o papel do juiz, mas fazer das próprias partes, quando possível, as protagonistas de suas próprias soluções. É resolver o problema antes que ele se torne processo. É validar o "direito de evitar a lide", numa atuação profilática e preventiva à crise de eficácia da justiça.

O sistema notarial e registral é um sistema secular e tem realizado muitas atividades no Brasil de modo eficiente e creditado. Todos os dias as pessoas procuram as serventias extrajudiciais para, em termos gerais, firmarem negócios jurídicos, atestarem autenticidade, certificarem fatos, etc., com ampla aceitação de todos os envolvidos. Não é incomum, no entanto, pequenos problemas surgirem entre os interessados e a solução ser intermediada pelos titulares (notários e registradores). Mas as funções notarial e registral poderiam prevenir ainda mais litígios judiciais se cultivassem uma cultura orgânica e institucional de resolução de conflitos baseados no diálogo, como é o caso da mediação e da negociação.

Nessa quadra de desafios é que procuramos nos assentar. Para tanto, desenvolvemos algumas noções acerca do conceito de "acesso à justiça", sobretudo a necessidade de promover uma releitura de seu significado. Logo após, abordamos sobre a importância de se pensar em mecanismos alternativos de resolução de conflitos, dando enfoque a caminhos que transcendem o Poder Judiciário, a exemplo da mediação. Em seguida, dedicamos um tópico ao grande desafio proposto neste artigo: permitir que o acesso à justiça, por meio de um de seus instrumentos (mediação extrajudicial), seja realizado pelo Direito Notarial. Daí a importância social desse estudo, que poderá contribuir para a efetivação de uma forma ativa de resolução de conflitos mais econômica, mais rápida e mais eficiente, no âmbito de um sistema de prestação de serviços públicos "extrajudiciais" já consolidado e amplamente presente em todas as comarcas brasileiras.

\section{A RESSIGNIFICAÇÃO DO CONCEITO DE “ACESSO À JUSTIÇA” FRENTE A CRISE INSTITUCIONAL DO JUDICIÁRIO BRASILEIRO}

\subsection{Acesso à Justiça}

“A lei não excluirá da apreciação do Poder Judiciário lesão ou ameaça a direito", art. $5^{\circ}, \mathrm{XXXV}$. O direito ao acesso à justiça, também conhecido como inafastabilidade da jurisdição, está consagrado na Constituição Federal de 1988. No mesmo sentido, a Declaração Universal dos Direitos Humanos, assegura, no artigo X, que "toda pessoa tem direito, em plena igualdade, a uma audiência justa e pública por parte de um tribunal independente e imparcial, para decidir de seus direitos e deveres ou do fundamento de qualquer acusação criminal contra ele" (BRASIL, 1988). 
O cotejamento dos dispositivos mencionados nos permite concluir que o acesso à justiça é direito fundamental constitucionalmente garantido e sintonizado com a Declaração Universal de 1948, sendo a sua concretização corolário do princípio da dignidade da pessoa humana, base do sistema normativo constitucional brasileiro. Na condição de direito fundamental, o acesso à Justiça deve ter aplicabilidade imediata e a intangibilidade de cláusula pétrea, retirada, portanto, da esfera de disponibilidade dos poderes constituídos.

No âmbito do processo, Cândido Rangel Dinamarco (1998, p. 304) revela que o acesso à justiça é a síntese de todos os princípios e garantias do processo, seja a nível constitucional seja infraconstitucional, seja em sede legislativa seja doutrinária e jurisprudencial. Logo, segundo a doutrina processualista, o acesso à Justiça é o princípio primeiro que abarca todos os demais princípios do processo.

Sob outro viés, o acesso à justiça é um dos valores fundamentais da própria democracia, podendo ser encarado como o mais básico dos direitos humanos, inserto em um sistema jurídico moderno e igualitário que pretenda garantir, e não apenas proclamar os direitos de todos (CAPPELLETTI; GARTH, 1988, p. 12). Assim, o problema fundamental em relação ao acesso à justiça não é o de justificá-lo, mas o de protegê-lo.

E proteger o acesso à justiça, frise-se, não se confunde a falsa ideia de ter acesso ao Judiciário. Nesse sentido, Dinamarco (2003, p. 114) afirma que o "Acesso à justiça é acesso à ordem justa, ou seja, obtenção de justiça substancial”. Complementarmente, Roberto Portugal Bacellar (2012, p. 40) afirma que o acesso à ordem jurídica justa dá-se pelo "acesso a métodos mais adequados à resolução dos conflitos, estejam eles dentro ou fora do Poder Judiciário".

Cappelletti e Garth (1988, p. 31-73) trataram das três ondas de acesso à justiça, baseados no fenômeno físico das ondas. Segundo os autores, a primeira onda consistiu na instituição da assistência judiciária gratuita às pessoas pobres. A segunda onda versou sobre os interesses difusos (transmudação da relação processual de natureza individual para a coletiva). E, por fim, a terceira onda tratou do alargamento da visão de acesso à justiça em comparação às duas ondas que a precederam. Enquanto as duas primeiras se ocuparam em enfocar os problemas pertinentes ao acesso ao Poder Judiciário, a terceira buscou dar novo enfoque ao conceito de acesso à justiça, voltando-se o olhar para a necessidade de se concretizar direitos.

Nesse sentido a manifestação de Capelletti (1991, p. 156):

A velha concepção, "tolemaica", consistia em ver o direito sobre a única perspectiva dos "produtores" e de seu produto: o legislador e a lei, a administração pública e o ato administrativo, o juiz e o provimento judicial. A perspectiva de acesso consiste, ao contrário, em dar prioridade à perspectiva do consumidor do direito e da justiça: o indivíduo, os grupos, a sociedade como um todo, suas necessidades a instância e aspirações dos indivíduos, grupos e sociedades, os obstáculos que se interpõem entre o direito visto como "produto" (lei, provimento administrativo, sentença) e a justiça vista como demanda social, aquilo que é justo. Acesso à justiça importa em meios legítimos, ou seja, instituídos por lei, para a solução de controvérsias. Não há em momento algum dessa experiência a pretendida correlação necessária com jurisdicionalização. 
Não havendo obrigatória correlação entre acesso à Justiça e jurisdicionalização, pode-se afirmar que a legitimação pelo Estado de outros órgãos para a resolução de litígios que não tenham em seu núcleo conteúdo jurisdicional, dispensando a interferência do Poder Judiciário, e mesmo a definição legal de requisitos que impliquem a manifestação do Estado-Juiz como última medida do processo resolutivo da lide, não significa qualquer negativa de acesso à ordem jurídica estatal.

A busca por novos instrumentos de acesso à justiça é defendida pela doutrina. Conforme Juvêncio Borges Silva (2013, p. 503):

A ampliação do acesso à justiça exige tanto uma ação por parte do Estado, de forma a criar as condições para a prestação de uma justiça mais célere e desburocratizada, haja vista que a morosidade processual é um dos maiores entraves do Judiciário no Brasil, quanto uma mudança de mentalidade por parte dos operadores do direito e das pessoas em geral, de sorte que novas possibilidades processuais e procedimentais sejam buscadas com vistas a uma efetivação crescente do acesso à justiça, garantindo destarte a realização de forma concreta deste direito fundamental.

Com efeito, o direito fundamental constitucional do acesso à Justiça é fundamento da mediação e da conciliação, que vai além do simples direito de demandar em juízo ou de ter uma razoável duração do processo. Prima-se, na teoria dos mecanismos consensuais de solução de conflitos (mediação e conciliação), pela qualidade na solução de conflitos, sobretudo daqueles onde as partes irão continuar se relacionando. Nestes casos, a solução construtiva e participativa do conflito é salutar para a manutenção da paz social, ao prevenir a má administração dos conflitos futuros.

\subsection{Crise do Judiciário e a necessária ressignificação do conceito de acesso à justiça}

Historicamente, o conceito de cidadão, dotado de direitos e deveres, foi enaltecido no Estado de Direito, após a superação do Estado absolutista, personificado na figura do soberano. Por meio da separação das funções, a ação estatal passou a ser controlada de maneira mais simples pelos cidadãos. Sem deixar de lado os enormes avanços proporcionados pelo Estado de Direito, tanto no modelo liberal quanto no social, a incapacidade sistêmica de prevenir injustiças, impedir governos autoritários e de propiciar uma verdadeira transformação social levou esse modelo ao fenecimento.

Como novo paradigma, o Estado Democrático de Direito apóia-se na intensa participação dos cidadãos para a construção da soberania popular, o fortalecimento da separação das funções em órgãos distintos, o respeito e promoção dos direitos fundamentais, a partir de um documento jurídico-político agudo: a Constituição. Conforme destacam Guerra Filho e Carnio (2013, p. 173): "o estado Democrático de Direito, então, representa uma forma de superação dialética da antítese entre os modelos liberal e social".

Deste modo, têm-se a tentativa de harmonizar interesses situados em três esferas distintas 
e muitas vezes conflitantes: a esfera pública, ocupada pelos entes estatais e toda a máquina pública; a esfera privada, em que se situa o indivíduo dotado de autonomia e liberdade e, por fim, a esfera coletiva, que atua de maneira intermediária, trazendo à baila as aspirações dos indivíduos enquanto membros de grupos politicamente organizados, formados para a obtenção de algum bem que ultrapassa meros desejos individuai (GERRA FILHO; CARNIO, 2013, p. 173).

No Brasil, os interesses conflitantes entre os mais diversos nichos sociais dificultaram a efetivação dos objetivos e o respeito aos direitos e garantias estampados no texto constitucional. Ou seja, o Brasil, no curso de toda sua história, experimentou problemas que acabaram por contribuir para esta situação. A enorme desigualdade social, a formação de uma cultura patrimonialista na qual o patrimônio público se confunde com o privado, uma entranhada cultura de corrupção que perpassa as práticas políticas em conivência com interesses privados, e tudo isto agravado pelo enorme distanciamento entre cidadãos e representantes políticos, que por sua vez conduz a uma falta de efetividade da própria Constituição, de vez que a concretização de direitos não se realiza em razão destes e outros obstáculos.

Estes fatores têm ocasionado uma legítima desconfiança da sociedade para com as instituições do Estado, o que agrava a crise institucional que atinge as esferas legislativa e executiva, que passam a atuar de maneira tímida e desprestigiada.

Em decorrência disso, o Poder Judiciário passa a ser protagonista em um sistema jurídicopolítico que busca efetivar, na maior medida possível, as promessas do Estado Democrático de Direito. Embora o protagonismo do Judiciário seja uma realidade global, fruto da "fluidez da fronteira entre política e justiça no mundo contemporâneo" (BARROSO, 2012, p. 1), o caso brasileiro se destaca em razão de sua intensidade ${ }^{1}$.

O excesso de judicialização dos conflitos tem provocado uma crise da justiça e a deslegitimação do Judiciário como Poder. Morosidade, dificuldade de enfrentamento das demandas mais complexas, resolução formal dos processos sem acabar com os conflitos, entre outros fatores, demonstram que o modelo tradicional de Jurisdição está esgotado e precisa ser perscrutado pela adoção de novas formas de solução de conflitos (ZANFERDINI, 2012, p. 237-253).

É notória a participação do Judiciário na vida institucional brasileira. Tal ingerência, como bem ressaltado por Barroso (2012), não é fenômeno exclusivo brasileiro, já que o protagonismo judicial pode ser visto em todas as partes do mundo envolvendo diversas questões de alcance político, de implementação de políticas públicas e de escolhas morais sobre os temais contestáveis na sociedade. Em vista disso, Barroso elenca causas prováveis a essa onda de judicialização.

Segundo Barroso (2012), existem três causas principais que justificam o excesso de judicialização no Brasil. A primeira, está relacionada ao processo de redemocratização do país com o advento da Constituição Federal de 1988. Para o autor, o Judiciário se tornou um poder político, apto a fazer valer a Constituição e as leis. Ao lado da expansão do Judiciário, o aumento pela demanda por justiça deu-se na medida em que o cidadão passou a agregar mais informação

1 Essa proeminência do judiciário, acentuada nos últimos anos, traz à baila ao menos três fenômenos, que possuem diferenças importantes: judicialização (da política e da vida), ativismo judicial e self-restraint (auto-contenção). Compreender tais fenômenos, além de delimitar importantes limites que não podem ser ultrapassados no âmbito constitucional, pode dar o diagnóstico da vitalidade de nossa democracia, de nossa carta política e do nosso judiciário. 
e consciência de seus direitos.

A segunda causa apontada por Barroso (2012) diz respeito à constituição abrangente. Com efeito, inúmeras disciplinas que antes eram decididas sob o crivo do processo político majoritário e da edição de leis foram inseridas no corpo constitucional. Logo, matérias constitucionais se tornam potenciais pretensões jurídicas, na medida em que Constituição é analítica e contempla inúmeros direitos individuais e prestações estatais.

Por último, a terceira causa apontada por Barroso (2012) refere-se ao sistema brasileiro de controle de constitucionalidade, considerado um dos mais abrangentes do mundo. A adoção de dois sistemas, difuso e abstrato, somada ao amplo rol de legitimados aptos a discutir a constitucionalidade das normas, são fatores que contribuem sobremaneira para uma enxurrada de ações capazes de discutir qualquer questão política ou moralmente relevante perante o STF.

$\mathrm{O}$ dogma de que a legalidade carrega consigo necessariamente a judicialização ${ }^{2}$ dos conflitos, presente desde sempre na consciência jurídica e na sistematização do direito pátrio e dos seus operadores, necessita de uma releitura à luz do pragmatismo, sob pena de brevemente haver um colapso total do sistema de jurisdição e, com isso, negação da própria tutela judicial enquanto direito constitucional fundamental.

Oportuna, nesse ponto, as observações de Costa e D’Oliveira (2014. p. 790):

Percebe-se, portanto, a retração e o descompasso entre a função jurisdicional do Estado e a complexidade das demandas sociais. Com efeito, diante das constantes mutações que marcam a sociedade globalizada, cada vez mais complexa e fragmentada; diante do surgimento de novas categorias de direitos e, por conseguinte, de sujeitos jurídicos legitimados a pleiteá-los; e, diante do aumento quantitativo e qualitativo das demandas sociais, cada vez mais específicas e intrincadas, o Poder Judiciário, enquanto estrutura hierarquizada, fechada e orientada por uma lógica legal-racional, passa a não mais atender, com celeridade e eficiência, às crescentes demandas que lhe são impostas.

Pelo exposto, o reconhecimento da impossibilidade da manutenção do atual modelo de entrega de jurisdição por parte do Estado, que acarreta a verdadeira "crise da justiça", fica evidente quando se percebe que inúmeras são as ferramentas alternativas (ou complementares) que o legislador e o próprio Poder Judiciário buscam construir como opção ao ato puro e simples de apresentar o litígio instaurado ao Estado-Juiz, no intuito de conseguir fornecer alguma resposta ao fenômeno crescente da judicialização. Verdadeiramente, esse agir não constitui outra coisa senão o reconhecimento de que o atual modelo não está conseguindo atingir seus objetivos.

Daí surge a necessidade de compreender a relação da mediação extrajudicial, do Direito Notarial e do Direito Constitucional, como instrumento efetivo de desafogamento do Poder Judiciário e de efetivação dos direitos constitucionais fundamentais, mormente quando tratamos do acesso à justiça, valor inegável na ordem constitucional vigente. Nesse sentido destaca Hesse (1991, p. 20): “Quanto mais o conteúdo de uma Constituição lograr corresponder à natureza

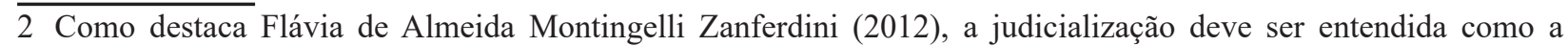
prerrogativa de acesso ao Poder Judiciário visando a realização de direitos individuais e/ou sociais. 
singular do presente, tanto mais seguro há de ser o desenvolvimento de sua força normativa."

Aliás, a força normativa está condicionada à possibilidade de realização dos conteúdos da Constituição, ou seja, da maior eficácia possível no desenvolvimento do conceito de acesso à justiça. Quanto mais ampla e profunda for a conexão de seus preceitos normativos com a historicidade e a realidade, afinada com o propósito de conservar e desenvolver a construção jurídico-social presente, maior será a perspectiva destes elementos desenvolverem a força normativa. Por outro lado, quando a Constituição ignora os elementos fomentadores do desenvolvimento político, econômico, social e espiritual do seu tempo, se vê incapaz de conservar e ampliar sua própria realização, situação que provoca a fragilidade da força normativa e a instabilidade jurídico-social para sua ruptura (CAMARGO, 2015).

\section{MECANISMOS ALTERNATIVOS DE RESOLUÇÃO DE CONFLITOS: CONSTRUÇÃO DE DIÁlOGOS À MEDIAÇÃO E CONCILIAÇÃO}

Uma correta compreensão do acesso à justiça, portanto, deve levar-nos à percepção de outros mecanismos de resolução de conflitos, que estejam para além do Poder Judiciário. É o que trataremos neste tópico.

\subsection{A necessidade de implementação dos mecanismos alternativos à resolução de conflitos}

O preâmbulo da Constituição Federal preleciona que a república brasileira é "fundada na harmonia social e comprometida, na ordem interna e internacional, com a solução pacífica das controvérsias" (BRASIL, 1988). Em que pese a nobre intenção do legislador constituinte, e do disposto na legislação infraconstitucional, mormente no Código de Processo Civil, ao instituir a audiência preliminar, visando à busca de conciliação entre as partes litigantes, o fato é que a ordem jurídica interna sempre foi ineficiente na busca de solução amigável das controvérsias, de vez que as audiências preliminares visando à conciliação eram realizadas pelo próprio juiz, com uma agenda apertada e tempo escasso para realizá-las, sem condições de levar a cabo um trabalho visando, de fato, à conciliação, além da falta de preparo da maioria dos juízes para este mister.

O esgotamento do Poder Judiciário, com sua quantidade enorme de processos, e com as dificuldades apontadas, contudo, indica a necessidade de uma mudança substancial nas velhas estruturas jurídicas. Se antes a preocupação era garantir o acesso de toda população ao Judiciário, tornando-o inafastável em caso de lesão ou ameaça a direito, agora se tem como prioridade a prestação efetiva e socialmente útil da Justiça. A alteração do paradigma beligerante para um que privilegia a autocomposição ${ }^{3}$ tornou-se uma medida inadiável para a sociedade brasileira.

A necessidade de autocomposição e a igual necessidade de tornar o processo mais dinâmico, com celeridade processual e descongestionamento da justiça, é medida cogente. Segundo o Conselho Nacional de Justiça

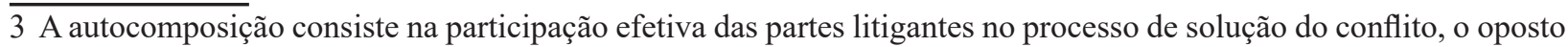
da heterocomposição que consiste em delegar a um terceiro (o juiz) a solução final do conflito através de uma sentença.
} 
O Poder Judiciário finalizou o ano de 2016 com 79,7 milhões de processos em tramitação, aguardando alguma solução definitiva. Desses, 13,1 ilhões, ou seja, 16,4\%, estavam suspensos ou sobrestados ou em arquivo provisório, aguardando alguma situação jurídica futura. Durante o ano de 2016, ingressaram 29,4 milhões de processos e foram baixados 29,4 milhões. Um crescimento em relação ao ano anterior na ordem de 5,6\% e 2,7\%, respectivamente. Mesmo tendo baixado praticamente o mesmo quantitativo ingressado, com Índice de Atendimento à Demanda na ordem de 100,3\%, o estoque de processos cresceu em 2,7 milhões, ou seja, em 3,6\%, e chegou ao final do ano de 2016 com 79,7 milhões de processos em tramitação aguardando alguma solução definitiva. [...] Tais fatores ajudam a entender o porquê de, apesar de se verificar um número de processos baixados quase sempre equivalente ao número de casos novos, o estoque de processos no Poder Judiciário (79,7 milhões) continua aumentando desde o ano de 2009, conforme demonstra a Figura 40. O crescimento acumulado no período foi de $31,2 \%$, ou seja, acréscimo de 18,9 milhões de processos. (BRASIL, 2017).

Ante o aumento do número de processos a morosidade da justiça é inevitável. De acordo com o resultado da Pesquisa de Clima Organizacional e Satisfação de Usuários, realizada em 2011, tanto os usuários da justiça, quanto os magistrados confirmaram que os processos não são concluídos no prazo previsto em lei. A pesquisa contou com a participação de 26.750 pessoas, sendo 803 magistrados, 7.259 servidores e 18.688 usuários do Poder Judiciário. Foi-lhes questionado acerca da conclusão temporânea dos processos, sendo confirmado por mais 80,3\% dos magistrados que os processos nunca são concluídos a tempo (CONSELHO NACIONAL DE JUSTIÇA, 2011, p. 16).

Em uma sociedade marcada pela "cultura do litígio", o modelo tradicional de justiça encontra sérias dificuldades para conseguir solucionar o congestionamento. Aliás, o próprio CNJ destaca em sua pesquisa que a quantidade de processos é muito maior que o atendimento da demanda, prevendo que "mesmo que o Poder Judiciário fosse paralisado sem ingresso de novas demandas, com a atual produtividade de magistrados e servidores, seriam necessários quase 2 anos e meio de trabalho para zerar o estoque" (BRASIL, 2015a, p. 34).

Em razão de tamanha urgência, revelada por dados estatísticos do próprio CNJ, observase nos últimos tempos o estímulo aos métodos alternativos de solução de conflitos, com destaque especial à conciliação e à mediação. Nesse sentido, a edição da Lei 13.140/2015, que regulamenta a mediação como meio de solução de controvérsias, e a promulgação do Novo CPC, que institui a audiência de conciliação ou mediação obrigatória, são provas inequívocas da maior preocupação com a prevenção e solução consensual de conflitos (BRASIL, 2015c).

Além disso, a Resolução 125/2010 do CNJ já mostrava a preocupação em valorizar soluções consensuais de conflitos ao instituir a "Política Judiciária Nacional de Tratamento dos Conflitos de Interesses", objetivando "assegurar a todos o direito à solução dos conflitos por meios adequados à sua natureza e peculiaridade". A solução consensual dos litígios constitui, além de incumbência estatal, dever de todos os operadores do Direito, que, antes de pensar em aplicar os instrumentos alternativos à resolução de conflitos, necessitam mudar a mentalidade ao 
operacionalizar o Direito (BRASIL, 2010).

Buscando alcançar essa mudança de mentalidade entre os que operacionalizam o Direito, estimulando e privilegiando o diálogo entre os cidadãos, o Novo CPC estabelece a audiência prévia de conciliação ou mediação como requisito obrigatório em todas as demandas judiciais. Embora soe estranho que essa audiência seja imposta, convém lembrar que a intenção é apenas fortalecer o diálogo e proporcionar a possibilidade de superação consensual do conflito.

A incessante busca por formas alternativas de resolução de conflitos faz com que a doutrina considere tais instrumentos essenciais, embora ainda haja muito preconceito com relação a essas técnicas. Rodolfo Mancuso (2011, p. 389-391) revela a falsa percepção de que o poder do magistrado possa ser abalado, ao retirar-se o poder de sentenciar os conflitos que lhe são encaminhados. Há ainda a concepção de que conciliar e mediar seriam técnicas menos nobres do que de julgar, ou de que a Justiça estatal seria reservada àqueles que podem arcar com seus custos, relegando à segunda classe os meios extrajudiciais. Para o autor, esse preconceito é atribuído em razão da pérfida ideia de que a sentença judicial põe fim ao conflito. Ao reverso, a sentença judicial encerra o processo e não necessariamente o conflito.

Para Mancuso (2011, p. 390) a adoção de técnicas diversas e adequadas, que ajudem na composição pacífica de conflitos é o que se deve buscar. Assim, os equivalentes jurisdicionais, a exemplo da conciliação, mediação, arbitragem e formas combinadas, constituem formas alternativas à solução adjudicada pelo Estado e de forma alguma pretendem concorrer com o Poder Judiciário, mas, do contrário, conviver. Possível, portanto, falar-se em "sistema pluriprocessual" com a coexistência de métodos.

Inúmeras são as vantagens desse paralelismo, tanto ao interessado/jurisdicionado quanto para o estado-juiz e administração da justiça, com ênfase à tendência de prestígio e cumprimentos pelas partes das "soluções encontradas pelos meios suasórios" e suas benéficas consequências, como, por exemplo, a redução de custos e de incertezas provenientes de um processo contencioso judicial. Em decorrência disso, será possível auxiliar na diminuição da sobrecarga infligida ao Judiciário, permitindo que esse construa melhores condições para entregar a prestação jurisdicional quando acionado, além de disseminar uma cultura de paz, que atende ao mandamento constitucional de solução pacífica de conflitos.

Kazuo Watanabe evidencia dois atores necessários à promoção de mudanças ao melhor acesso da justiça. O Estado deve ser entendido como o primeiro ator, a quem incumbe "organizar todos esses meios alternativos de solução dos conflitos ao lado dos mecanismos tradicionais e formais já em funcionamento". Esclarece o autor que "tais serviços, que podem ser informais, não precisam estar organizados dentro do Poder Judiciário" (WATANABE, 1988, p. 133). Relaciona, como exemplos, entidades públicas não pertencentes ao Judiciário e entidades privadas. O segundo ator destacado por Watanabe (1988) é a participação da comunidade na administração da justiça. À época, já sugeria a criação de Juizados Informais de Conciliação.

\subsection{Mediação e conciliação: soluções que transcendem o Poder Judiciário}

SCIENTIA IURIS, Londrina, v. 22, n. 3, p. 88-110, nov. 2018. DOI: 10.5433/2178-8189.2018v22n3p88 
Seguindo a tendência do direito comparado, a mediação passou a ser regulada pelo Novo Código de Processo Civil (Lei 13.105/2015) e pela Lei de Mediação (Lei 13.140/2015). Conforme parágrafo único do art. $1^{\circ}$ da lei "Considera-se mediação a atividade técnica exercida por terceiro imparcial sem poder decisório, que, escolhido ou aceito pelas partes, as auxilia e estimula a identificar ou desenvolver soluções consensuais para a controvérsia”. Trata-se, portanto, de um instrumento de solução de conflitos entre os interessados e de autocomposição no âmbito da administração da justiça (BRASIL, 2015c, 2015c).

Conforme Roberto Portugal Bacellar (2012, p. 85), o conceito de mediação,

[...] além de processo, é arte e técnica de resolução de conflitos intermediada por um terceiro mediador (agente público ou privado) - que tem por objetivo solucionar pacificamente divergências entre pessoas, fortalecendo suas relações [...], proporcionando os laços de confiança e os compromissos recíprocos que os vinculam.

Do conceito acima, extrai-se que a mediação é um processo (feixe de atos jurídicos), ou seja, uma atividade desenvolvida em fases, que visa à solução do conflito pelos próprios interessados com a ajuda de um terceiro imparcial. Tem como traço marcante o controle do processo pelas partes (emporwement), assentado na ideia de que é nas pessoas - na atitude voluntária das partes - que reside a solução do problema.

No direito comparado Cohen (2011), especialmente no direito anglo-saxão, verificam-se dois modelos de mediação: no primeiro, chamado de facilitative mediation, o trabalho do medidor deve ser o menos visível possível. O procedimento da mediação consiste em perguntas feitas pelo mediador, validação dos pontos de vista de cada parte e busca de interesses intrínsecos de cada parte, ou seja, o motivo por que elas escolheram defender um determinado ponto de vista. Já no segundo, denominado evaluative mediation, o mediador exerce papel ativo, apresentando propostas de acordos. É o que se denomina de análise do risco do conflito (litigation risks analysis), pois este concederá uma previsão de como o conflito irá terminar.

No Brasil, a Lei 13.140/2015 não faz distinção entre os modelos e representa um significativo e irrepreensível avanço em direção ao dinamismo das relações e a desjudicialização das demandas. Em seus 48 artigos, a lei busca sistematizar tanto a mediação judicial quanto a mediação extrajudicial. Merece especial destaque a possibilidade da mediação e transação em conflitos envolvendo Pessoas Jurídicas de Direito Público, desde que preenchidos alguns requisitos. Além disso, destaca-se o estabelecimento dos seguintes princípios em seu art. $2^{\circ}$ : I - imparcialidade do mediador; II - isonomia entre as partes; III - oralidade; IV - informalidade; V - autonomia da vontade das partes; VI - busca do consenso; VII - confidencialidade e VIII - boa-fé (BRASIL, 2015c).

Tendo como norte os princípios acima, o processo de mediação extrajudicial pode ser iniciado de duas formas. Na primeira, as partes decidem submeter um conflito à mediação a partir do aparecimento da diferença. Nesse caso, é necessário que uma das partes proponha à outra a ideia de tentar resolver o conflito entre elas mediante um terceiro imparcial, sem poder decisório. 
É essencial, desse modo, que cada uma das partes se convença da utilidade e da conveniência desse meio para a solução de conflito estabelecido entre elas. Para que seja possível esse processo de convencimento é necessário assegurar informações adequadas sobre essa forma de solução de conflitos, o que poderá se dar com o auxílio de profissionais ou associações envolvidas na divulgação da mediação e outras formas alternativas de resolução de conflitos (COHEN, 2011).

$\mathrm{Na}$ segunda forma de início da mediação vislumbra-se a existência de cláusula compromissória ou de mediação. Trata-se de cláusula análoga à de um contrato jurídico de natureza patrimonial, pela qual as partes estipulam que eventual conflito ou diferença decorrente do negócio jurídico será submetido à resolução por meio da mediação ou de outra forma alternativa de solução de controvérsias, como a arbitragem, antes de qualquer recurso ao Judiciário. Nesse caso, a vontade das partes de se socorrer à mediação é manifestada antes da ocorrência do conflito, vale dizer, por ocasião da celebração do contrato. Nele são estabelecidos os prazos para realização das reuniões da medição, o local de sua realização e a escolha do mediador ou da equipe de mediação, além de penalidade em caso de não comparecimento à reunião do art. 22 da Lei 13.140/2015 (BRASIL, 2015c).

Com a permissão da cláusula contratual de mediação estamos diante de hipótese de mediação obrigatória, e o magistrado, em caso de propositura de ação judicial, está autorizado a suspender o processo por prazo suficiente para a solução consensual do conflito (BRASIL, 2015c, art. 16). Configura-se, portanto, hipótese legal de obrigatoriedade da mediação. O Novo Código de Processo Civil (NCPC), ao tratar das "Normas Fundamentais do Processo Civil”, dispõe que "A conciliação, a mediação e outros métodos de solução consensual de conflitos deverão ser estimulados por juízes, advogados, defensores públicos e membros do Ministério Público, inclusive no curso do processo judicial" (BRASIL, 2015b, art. $1^{\circ}, \S 3^{\circ}$, grifo nosso), remetendo a ideia de que estamos diante de um poder-dever estabelecido pelo Estado-juiz. Esse é o mesmo entendimento extraído dos art. $3^{\circ}, 27^{\circ}$ da Lei de Mediação, especialmente esse último, cuja redação reproduzimos: "Art. 27. Se a petição inicial preencher os requisitos essenciais e não for o caso de improcedência liminar do pedido, o juiz designará audiência de mediação”. (BRASIL, 2015c, grifo nosso).

De ressaltar que, ainda no período de vacatio legis do NCPC, já se instaurou uma celeuma hermenêutica com a edição da Lei de Mediação. Isso porque a Lei de Mediação, ao tratar do tema, não repete a possibilidade de que ambas as partes possam opor-se, em consenso, à realização da audiência de mediação, como se extrai do $\S 5^{\circ}$ do art. 334 do NCPC: "§ $5^{\circ} \mathrm{O}$ autor deverá indicar, na petição inicial, seu desinteresse na autocomposição, e o réu deverá fazêlo, por petição, apresentada com 10 (dez) dias de antecedência, contados da data da audiência" (grifo nosso). Estamos diante de antinomia de normas, que deverá ser resolvida mediante o critério da especialidade. Assim, a Lei de Mediação se sobrepõe à regulação do NCPC, pois se trata de lei especial (Lex specialis derogat generali) e de lei posterior (lex posterior derogat legi priori) (DUARTE, 2015).

De resumir, desse modo, que a Lei de Mediação (art. 27) não repete a possibilidade 
de oposição à realização da audiência, consignando, apenas, que preenchidos os requisitos essenciais e não sendo o caso de improcedência liminar do pedido, "o juiz designará audiência de mediação". O verbo "designar", aqui conjugado no futuro do presente, exprime um poderdever do magistrado. O poder-dever é caracterizado por ser uma competência atribuída por lei (poder), ao mesmo tempo em que essa atribuição é um comando imperativo (dever), de tal sorte que não somente pode fazê-lo, como deve fazê-lo. Logo, a mediação, no Direito Brasileiro não é mera faculdade, mas técnica obrigatória (BRASIL, 2015c).

A mediação pode ter por objeto direitos disponíveis e indisponíveis. Nesse último caso, o acordo somente terá validade depois de ouvido o Ministério Público e da homologação judicial - é exemplo o acordo que envolve alimentos, que têm conteúdo patrimonial. Direitos patrimoniais, aliás, são o objeto central da mediação, já que é mais comum estarmos diante de situações que envolvam valor econômico. Destarte, direitos obrigacionais, creditícios, pessoais e reais, podem ser objeto de mediação, ao passo que os direitos extrapatrimoniais têm alcance reduzido quando se trata de mediação (direito à imagem, por exemplo).

Vistas algumas premissas objetivas estabelecidas na Lei de Mediação e no Novo CPC, podemos definir como finalidades da legislação que rege a matéria: (i) a construção da comunicação entre as partes envolvidas, criando espaços para que os pontos relevantes do litígio sejam expostos de forma tranquila; (ii) a mudança comportamental das partes, para que reajam positivamente ao conflito, transmutando o estado de desequilíbrio em que se encontram inicialmente; (iii) a tentativa de preservar o relacionamento das partes, enfatizando-se o respeito, a ética, proporcionando oportunidade para a transformação do padrão contencioso, estabelecendo um espírito de colaboração; (iv) a prevenção de novos conflitos, estancando o crescimento da adversariedade e litigiosidade, afastando sentimentos de desforra, de vitória ou derrota; e, por fim, (v) a inclusão social, pela participação democrática de diversos segmentos da sociedade, concretizando valores de cidadania e convivência social (LAMANAUSKAS, 2015, p. 78-79).

Conforme se verifica, a superação da crise enfrentada pelo Poder Judiciário passa também pela construção de uma sociedade mais harmônica e madura, capaz de solucionar suas próprias divergências em busca de um desenvolvimento saudável do sistema de Justiça. A consolidação da mediação no contexto brasileiro contribui, nesse sentido, para a pacificação social ao promover o diálogo como fator preponderante para a resolução de conflitos, aperfeiçoando o acesso à justiça. Não se pode olvidar que o tratamento do conflito deve ser visto em caráter multidisciplinar, com a inclusão de outros sistemas, órgãos e entidades. Logo, a institucionalização dos meios consensuais de resolução de conflitos representa maiores possibilidades de sucesso. Não é outra a opinião do doutrinador Celso Campilongo (2013), que afirma: “Outras organizações que contribuam para a concretização do direito - especialmente segmentos reconhecidos pela população, com serventias extrajudiciais - também são bem-vindas".

\section{PARA ALÉM DAS FORMALIDADES DO CONFLITO: O DESAFIO DA ATIVIDADE NOTARIAL NA MEDIAÇÃO EXTRAJUDICIAL}


Como se depreende das análises realizadas por José Eduardo Faria (2004), as dificuldades da Jurisdição tradicional se agravaram com a crise do Estado Social e com o advento da globalização econômica. Essa fase da história é paradigmática e se constitui numa nova e complexa realidade a ser tratada pela ciência jurídica. O direito contemporâneo, resultado de uma elaboração em curso, desconhece limites de tempo e de espaço, reduz significativamente as fronteiras entre as nações, pulveriza o processo de produção de mercadorias e cria redes de mercados, torna o capital financeiro um agente especulador sem nacionalidade e sem controle estatal, enfim, faz com que a política seja substituída pelo mercado como espaço máximo de regulação e de controle social.

O processo de exclusão social é intensificado pela aposta no projeto global de mercado, que prima pelo reinado do lucro e diminui as potencialidades das políticas públicas dos Estadosnação. Novas formas de conflitividade são geradas a partir de novos focos de pressão social, pois os conflitos de massa, étnicos e culturais redefinem a pauta de demandas sociais e jurídicas, exigindo uma ampliação e qualificação do poder jurisdicional tanto no âmbito externo quanto no interno (FARIA, 2004).

A sociedade contemporânea evidencia um novo momento histórico, centrado na celeridade e no risco das relações, na transposição dos espaços geográficos de produção econômica e jurídica, na construção de novos locais de decisão e de influência, na conflitividade complexa, características que têm levado a uma crise de identidade funcional das instituições modernas, da qual o Poder Judiciário não ficou isento.

As pressões provocadas pela desterritorialização do processo produtivo, pela transnacionalização dos mercados, pela redefinição de tempo e de espaço, pela rapidez e incerteza das relações sociais, pelas demandas cada vez menos estandardizadas, caracterizam o cenário contemporâneo como bastante distinto daquele no qual o Poder Judiciário, nos moldes pensados pelo moderno Estado de Direito, estava acostumado a interferir (FARIA, 2001).

Definitivamente a jurisdição precisa se reinventar em termos quantitativos e qualificativos. Precisa construir uma nova dinâmica de intervenção, mais criativa, conectada com as demandas do tempo em que opera, ágil para fazer frente à complexidade que afeta todos os níveis da vida cotidiana e, ao mesmo tempo, suficientemente madura e habilidosa para conviver e dialogar com novos espaços de produção do direito e da decisão jurídica. É nesse sentido que os mecanismos alternativos de solução de conflitos pretendem ressignificar o litígio, o seu tempo, a sua processualidade, os seus atores, ao envolver ativamente as partes na construção dialogal de sua própria decisão (SPLENGER, 2010). É o caso da mediação e da negociação.

Por se tratar de um espaço privilegiado, já consagrado em nossos serviços públicos e creditado pela institucionalidade jurídica, o serviço notarial poderá avançar nesse campo, ampliando sua capacidade de ação para resolver um conjunto de controvérsias sem a necessidade de ajuizamento da ação. Muitas demandas poderiam ser evitadas no âmbito notarial com a proposição ativa do diálogo e com o empoderamento das partes. 
É certo que o desenvolvimento histórico notarial deu novas feições às funções do tabelião, variando de acordo com as tradições jurídicas e políticas de cada país. No Brasil, com a promulgação da Constituição Federal de 1988, o tabelião

[...] assume o ápice da sua evolução, passando a ser um profissional do direito cuja função vai muito além da redação negocial. O notário passa a ter a função de receber a manifestação de vontade das partes, qualificar juridicamente esta vontade, rechaçando as ilicitudes que porventura contenha, e instrumentalizando o ato jurídico adequado a dar vazão àquela vontade (BRANDELLI, 2011, p. 169).

Ao realizar a intervenção notarial, os interessados têm como fim garantir a segurança e a prova dos atos e negócios praticados e se munir de instrumentos capazes de gerar toda a carga eficacial que tende o negócio jurídico nele consubstanciado, como forma de lograr estabilidade nas relações jurídicas. É, pois, a materialização da segurança jurídica, valor essencial do Direito, que implica equilíbrio e certeza das regras que regem as relações intersubjetivas.

Ao lado da segurança jurídica, verifica-se a função acautelatória ou preventiva de conflitos, denominada por Leonardo Brandelli de profilaxia jurídica. Essa tendência profilática, em apertada síntese, pode ser determinada pelo "direito de evitar a lide". Como sabido, o desenvolvimento saudável das relações humanas impõe o fomento de mecanismos aptos a evitar os conflitos e a lide. Assim, o incentivo a instituições que promovam a paz social sem a ingerência coativa da jurisdição merece destaque no atual estágio de desenvolvimento do Direito.

O notário, então, atua no desenvolvimento voluntário do direito, a fim de garantir a segurança e a certeza jurídica preventiva às relações privadas. Conforme o Min. Carlos Ayres Britto, "o modo usual de atuação do Poder Judiciário se dá sob o signo da contenciosidade, enquanto o invariável modo de atuação das serventias extra-forenses não adentra essa delicada esfera da litigiosidade entre sujeitos de direito" (BRASIL, 2012).

$\mathrm{O}$ assessoramento jurídico imparcial promovido pelo notário permite-lhe ser confiada a função de consultor jurídico, encarregado de analisar, aconselhar e interpretar as situações jurídicas apresentadas, apontando para o cumprimento espontâneo do direito, em caráter cautelar, prevenindo futuros litígios. Disso decorre a política jurídica desempenhada pelo profissional, que verifica a juridicidade da situação e a possibilidade de aplicação do ato notarial, de acordo com as máximas do Direito.

Acentua-se, ainda, a função de mediador, uma vez que escuta a vontade declarada pelas partes e encontra o instrumento adequado para a realização de tais desígnios, desde que juridicamente possíveis, imprimindo-lhe validade e eficácia. Tal documento se perpetua no tempo, com força de fé pública, decorrente do caráter autenticante da função notarial. Noutras palavras, a interferência do notário torna o instrumento autêntico, permeado pela presunção juris tantum de veracidade, decorrente de sua fé pública.

Possibilitar que o Tabelião atue como mediador implica em analisar algumas premissas da legislação afeta a atividade notarial no Brasil estabelecidas na Lei 8.935/1994. Inicialmente, temos que o notário não detém competência territorial para atuar em outros municípios que não 
o de sua Comarca. Conforme preceitua o art. $9^{\circ}$ da Lei 8.935/1994, o tabelião de notas não pode praticar "atos de seu ofício" fora do município para o qual recebeu a delegação. Logo, cinge-se a controvérsia no sentido de saber se a mediação seria ou não ato de ofício do Tabelião (BRASIL, 1994).

Se uma das funções do notário é justamente atuar como assessor jurídico e imparcial, emprestando fé pública aos negócios jurídicos e impingindo em seus atos a segurança jurídica necessária, parece-nos que a mediação se enquadraria dentre as atribuições ofertadas ao Tabelião. Logo, superada a análise no tocante à competência material do notário para atuar nos atos e negócios jurídicos extrajudiciais, deve-se atentar para o fato de que a atuação notarial deve obedecer à territorialidade imposta pela legislação que rege a matéria. Noutras palavras, o Tabelião pode atuar como mediador nas matérias que lhe são afetas (competência material), mas não pode extrapolar os limites de sua comarca (competência territorial).

Como visto, a seara de atuação do notário é a preventiva. Uma vez empossado na figura de mediador, o Tabelião deve ser sujeito imparcial, que busca aproximar e aconselhar as partes, formalizar juridicamente suas vontades e velar pela validade e eficácia de modo a evitar que o acordo seja fonte de conflitos futuros. No exercício da profilaxia notarial, a mediação extrajudicial poderá diminuir a lide, entendida essa como um "conflito de interesses degenerado pela pretensão de uma das partes e pela resistência da outra" (CÂMARA, 2011, p. 76).

Como se disse, os notários já são autoridades creditadas e desempenham seu papel de forma institucional, o que potencializa sua função com capacidade de intervir, de mediar, de propor espaços de fala e de alteridade que podem levar à produção de uma solução pelos próprios envolvidos. Trata-se de mais uma possibilidade, de mais uma alternativa, e não de uma solução miraculosa para o problema da jurisdição. O fato de estar presente de modo institucionalizado em todas as comarcas brasileiras, contar com profissionais com formação em direito, ser uma certificadora de atos jurídicos, credencia a função notarial a contribuir para a produção de novos espaços complementares para se construir soluções para problemas jurídicos.

Uma frase bastante conhecida do processualista italiano Carnelutti, citada pela maioria dos autores brasileiros que se dedicam ao direito notarial e registral, refere que "quanto mais notário menos juiz" (CAMPILONGO, 2014, p. 21). Uma atuação preventiva e mediadora do notariado pode construir muitas soluções dialogais e impedir que muitos processos judiciais se iniciem. É, pois, a profilaxia a serviço da doença crônica denominada inefetividade e morosidade judicial.

Com o advento da Lei $\mathrm{n}^{\mathrm{o}} 13.140 / 2015$ surgiu a possibilidade de a atividade notarial contribuir ainda mais para o cenário jurídico, ao permitir a institucionalização, no âmbito de sua competência, das atividades de mediação. Parece-nos que a atividade notarial poderá ser mais bem utilizada do que já é, ampliando sua capacidade de intermediação entre as partes na direção de prevenir a violação de direitos pela promoção conservatória do diálogo. Observa-se que, para o exercício da mediação, o notário necessariamente precisaria comprovar ter realizado curso credenciado de mediação, de forma a estar apto para o exercício de tal função, nos termos da Lei 13.140, art. $9^{\circ}$ (BRASIL, 2015c). 
Registre-se, por fim, que a função notarial não é judicial e tampouco administrativa: é uma função pública que tem por finalidade assegurar a validade dos negócios jurídicos, a segurança jurídica e a prevenção de conflitos, contribuindo, consequentemente, para a manutenção da paz social. Enquanto a decisão judicial se baseia em um poder ou jurisdição que emana do Estado, a função cautelar ou preventiva pelo notário responde igualmente a um poder estatal erigido sob um regime especial, que visa garantir os direitos individuais, a paz social e a estabilidade nas relações humanas.

Como visto, o excesso de judicialização dos conflitos tem provocado uma crise da justiça e a deslegitimação do Judiciário como Poder. Morosidade, dificuldade de enfrentamento das demandas mais complexas, resolução formal dos processos sem acabar com os conflitos, entre outros fatores, demostram que o modelo tradicional de Jurisdição está esgotado e precisa ser perscrutado pela adoção de novas formas de solução de conflitos (ZANFERDINI, 2012, p. 237253).

O modelo de processo que afasta as partes, que as impedem de participar ativamente de suas próprias soluções definitivamente esgotou-se. Em muitos casos somente as próprias partes é que poderão encontrar e produzir uma solução para ao seu conflito. É na cultura dialogal, democrática e participativa que apostam os mecanismos alternativos de resolução de conflitos, como a mediação e a negociação. Obviamente que nem todos os conflitos poderão ser mediados, mas certamente que muitos que hoje não são teriam resultados bem melhores e definitivos se as próprias partes tivessem uma participação ativa na produção de uma solução para o seu problema.

A mediação funciona, destaca Spengler (2010, p. 320)

[...] como espaço democrático, uma vez que trabalha como a figura do mediador que, ao invés de se posicionar em local superior às partes, se coloca no meio delas, partilhando de um espaço comum e participativo, voltado para a construção do consenso num pertencer comum.

Foi atentando, certamente, para esta nova realidade, que o Conselho Nacional de Justiça, através do Provimento 67 de março de 2.018, decidiu que os cartório de todo o país poderão oferecer o serviço de mediação e conciliação judicial, antes exclusivos dos Tribunais de Justiça, sendo que o serviço pode ser pretado imediatamente. Como observou o CNJ “o objetivo é ampliar a oferta de métodos consensuais de solução de conflitos utilizando a capilaridade dos cartórios de todo o País". (ANDRADE, 2018). Neste sentido informou também o CNJ:

Cada cartório atuará dentro da sua área de expertise e sob regulamentação e supervisão dos Núcleos Permanentes de Métodos Consensuais de Solução de Conflitos (Nupemec) da jurisdição e das corregedorias-gerais de justiça (CGJ) dos Estados e do Distrito federal e dos Territórios. Os acordos firmados serão inseridos pelos cartórios em um sistema eletrônico dos Nupemec, que por sua vez fornecerão os dados para a Corregedoria Nacional. As informações estatísticas sobre o volume de acordos firmados e cartórios que mais mediam acordos estarão disponíveis na página eletrônica do Conselho Nacional de Justiça (CNJ), para consulta pública (ANDRADE, 2018). 
Ainda que este tenha sido um importante avanço no que se refere ao acesso à justiça e que, certamente contribuirá para uma maior celeridade na resolução de conflitos, através da autocomposição, que redunda em uma solução de fato do conflito, faz-se necessário que outro passo seja dado, qual seja, a alteração da Lei 13.140/2015 (Lei da Mediação) no sentido de inserir na legislação a atividade notarial na resolução de conflitos pela via da mediação e conciliação.

\section{CONCLUSÕES}

O Estado Democrático de Direito ainda é a melhor maneira de organizar politicamente a sociedade. Para seu êxito, contudo, os limites e disposições constitucionais devem ser respeitados. A efetivação e o respeito aos direitos fundamentais são as maiores vitórias do Estado Constitucional, resguardá-las é um dever. Assim, o acesso à justiça deve ser reconhecido como um dos valores inegociáveis do Estado Democrático de Direito.

O Poder Judiciário é protagonista de um sistema jurídico-político que atravessa uma crise de eficiência, não conseguindo fornecer respostas eficazes à necessidade de resolução de conflitos. O problema do excesso de demandas e conflitos tem provocado a deslegitimação do Judiciário como Poder: morosidade, dificuldade de enfrentamento das demandas complexas, resolução formal dos processos sem acabar com os conflitos, entre outros fatores, demonstram que o modelo tradicional de Jurisdição está esgotado e precisa ser repensado à luz de mecanismos alternativos de solução de conflitos.

Por se tratar de um espaço privilegiado, já consagrado em nossos serviços públicos e creditado pela institucionalidade jurídica, o serviço notarial e registral poderá avançar nesse campo, ampliando sua capacidade de ação para resolver um conjunto de controvérsias sem a necessidade de ajuizamento da ação. Trata-se da possibilidade da mediação extrajudicial. Com essa técnica, muitas demandas podem ser evitadas com a proposição ativa do diálogo e com o empoderamento das partes. Como se disse, os Tabeliães já são autoridades creditadas e desempenham seu papel de forma institucional, o que potencializa sua função com capacidade de intervir, de mediar, de propor espaços de fala e de alteridade que podem levar à produção de uma solução pelos próprios envolvidos.

Trata-se de mais uma possibilidade, de mais uma alternativa, e não de uma solução miraculosa para o problema da "crise da jurisdição". O fato de estar presente de modo institucionalizado em todas as comarcas brasileiras, contar com profissionais com formação em direito, ser uma certificadora de atos e negócios jurídicos, credencia a função notarial a contribuir para a produção de novos espaços complementares para se construir soluções para problemas jurídicos.

No âmbito acadêmico, por sua vez, apesar de a mediação (e outras formas alternativas de resolução de conflitos) ser amplamente estudada, pouca repercussão suscitou quando relacionada às atividades notarias e registrais. A lei que trata da mediação é recente, de julho de 2015 , e os 
posicionamentos (teóricos e das entidades de classe) a respeito de sua possibilidade e vantagens no âmbito notarial e registral são escassos e muitas vezes antagônicos. Daí a motivação do presente trabalho, visando auxiliar a comunidade jurídica e política na implementação de modelos eficientes e teoricamente bem fundamentados.

Neste sentido, entendemos que o presente artigo traz para o universo jurídico uma significativa contribuição, pois coloca a possibilidade de ampliar a discussão do acesso à justiça pela via notarial, pelos motivos já expostos, tendo em vista que é do conhecimento público que em regra a prestação de serviços realizados pelos cartórios é incomparavelmente mais célere que os serviços prestados pelo poder judiciário, além de ser eficiente e eficaz, pois são revestidas de fé pública.

O passo dado pelo CNJ em autorizar a realização da mediação e da conciliação pelos cartórios certamente contribuirá para a regulamentação definitiva desta nova modalidade de acesso à justiça, o que beneficiará de forma significativa a coletividade, além de contribuir para a redução dos processos no âmbito judicial.

\section{REFERÊNCIAS}

ANDRADE, Paula. Cartórios poderão oferecer serviços de mediação e conciliação judicial. Agência CNJ de Noticias, Brasília, 28 mar. 2018. Disponível em: <http://www.cnj.jus.br/noticias/ cnj/86416-cartorios-poderao-oferecer-servico-de-mediacao-e-conciliacao-judicial $>$. Acesso em: 8 jul. 2018.

BACELLAR, Roberto Portugal. Mediação e arbitragem. São Paulo: Saraiva, 2012.

BARROSO, Luís Roberto. Judicialização, ativismo judicial e legitimidade democrática. (SYN)THESIS, Rio de Janeiro, v. 5, n. 1, p. 23-32, 2012. Disponível em: <http://www.epublicacoes.uerj.br/index.php/synthesis/article/view/7433>. Acesso em: 15 jan. 2017.

BITTAR, Eduardo C. B.; ALMEIDA, Guilherme Assis de. Curso de filosofia do direito. São Paulo: Gen-Atlas, 2017.

BRANDELLI, Leonardo. Teoria geral do direito notarial. 4. ed. São Paulo: Saraiva, 2011.

BRASIL. Conselho Nacional de Justiça. Justiça em números 2015: ano-base 2014. 11. ed. Brasília, 2015a.

BRASIL. Conselho Nacional de Justiça. Justiça em números: ano 2017: ano-base 2016.

Brasília, 2017. Disponível em: <http:/www.cnj.jus.br/files/conteudo/arquivo/2017/12/b60a659e5d5cb79337945c1dd137496c.pdf>. Acesso em: 6 mar. 2018.

BRASIL. Conselho Nacional de Justiça. Resolução 125/2010. Disponível em: < http://www.cnj. jus.br/busca-atos-adm?documento=2579>. Acesso em: 12 jan. 2017. 
BRASIL. Constituição (1988). Constituição da República Federativa do Brasil. <http://www. planalto.gov.br/ccivil_03/constituicao/constituicao.htm>. Acesso em: 6 mar. 2018.

BRASIL. Lei No 13.105, de 16 de março de 2015. Código de Processo Civil. 2015b. Disponível em: <http://www.planalto.gov.br/ccivil_03/_ato2015-2018/2015/lei/113105.htm>. Acesso em: 6 mar. 2018.

BRASIL. Lei $\mathbf{N}^{0} \mathbf{1 3 . 1 4 0}$, de 26 de junho de 2015. Dispõe sobre a mediação entre particulares como meio de solução de controvérsias e sobre a autocomposição de conflitos no âmbito da administração pública; altera a Lei no 9.469, de 10 de julho de 1997, e o Decreto n⿳0 70.235, de 6 de março de 1972; e revoga o $\S 2^{\circ}$-do art. $6^{\circ}$ da Lei no 9.469 , de 10 de julho de 1997. 2015c. Disponível em: <http://www.planalto.gov.br/ccivil_03/_ato2015-2018/2015/Lei/L13140.htm>. Acesso em: 12 jan. 2017.

BRASIL. Lei $N^{\mathbf{0}}$ 8.935, de 18 de novembro de 1994. Regulamenta o art. 236 da Constituição Federal, dispondo sobre serviços notariais e de registro. (Lei dos cartórios). Disponível em: $<$ http://www.planalto.gov.br/ccivil_03/leis/L8935.htm>. Acesso em: 12 jan. 2017.

BRASIL. Supremo Tribunal Federal. Ação direta de inconstitucionalidade ADI 2.415-SP. Relator: Ministro Ayres Britto. Brasília, 7 de março de 2012. Diário Oficial da Justiça, São Paulo, n. 052, p. 1-34, 13 mar. 2012. Disponível em: <http://www.stf.jus.br/portal/cms/ verNoticiaDetalhe.asp?idConteudo=189957>. Acesso em: 12 jan. 2017.

CÂMARA, Alexandre Freitas. Lições de direito processual civil. 21. ed. Rio de Janeiro: Lumen Juris, 2011. v. 1.

CAMARGO, Nilton Marcelo de. Konrad Hesse e a teoria da força normativa da Constituição. Revista Jurídica UNIGRAN, Dourados, MS, v. 17, n. 33, jan./jun. 2015.

CAMPILONGO, Celso Fernandes. A mediação e o notariado. Disponível em: $<$ http://www. arpensp.org.br/?pG=X19leGliZV9ub3RpY2lhcw==\&in=MTg4NDI=>. 2013. Acesso em: 14 jan. 2017.

CAMPILONGO, Celso Fernandes. Função social do notariado: eficiência, confiança e imparcialidade. São Paulo: Saraiva, 2014.

CAPPELLETTI, Mauro. Algunas reflexiones sobre el rol de los estúdios processales en la actualidad. Revista de Processo, São Paulo, n. 64, p. 148-159, set. 1991.

CAPPELLETTI, Mauro; GARTH, Bryant. Acesso à justiça. Tradução de Ellen Gracie Northfleet. Porto Alegre: Fabris, 1988.

COHEN, Diane. Evaluative mediation. Disponível em: < http://www.mediate.com/articles/ 
CohenDbl20110321.cfm>. 2011. Acesso em: 10 jan. 2017.

CONSELHO NACIONAL DE JUSTIÇA. Pesquisas Judiciárias. Pesquisa de satisfação e clima organizacional. Brasília, 2011.

COSTA, Marli Marlene Morais; D’OLIVEIRA, Mariane Camargo. A ressignificação do estado democrático contemporâneo instrumentalizada pelo exsurgimento de uma nova cultura políticojurídica de acesso à justiça: uma (re)construção da matriz principiológica constitucional na materialização de direitos. Revista Novos Estudos Jurídicos: Eletrônica, Itajaí, SC, v. 19, n. 3, p. 787-807, set./dez. 2014. Disponível em: $<$ http://siaiweb06.univali.br/seer/index.php/nej/article/ view/6669/pdf>. Acesso em: 12 jan. 2017.

DINAMARCO, Cândido Rangel. A instrumentalidade do processo. 6. ed. São Paulo: Malheiros, 1998.

DINAMARCO, Cândido Rangel. Instituições do processo civil. 3. ed. São Paulo: Malheiros, 2003. V. 1.

DUARTE, Zulmar. A difícil conciliação entre o Novo CPC e a Lei de Mediação. 2015. Disponível em: $<$ http://jota.info/artigos/a-dificil-conciliacao-entre-o-novo-cpc-e-a-lei-demediacao-17.08.2015>. Acesso em: 14 jan. 2017.

FARIA, José Eduardo. O direito na economia globalizada. São Paulo: Malheiros, 2004.

FARIA, José Eduardo. O poder judiciário nos universos jurídico e social: esboço para uma discussão de política judicial comparada. Revista Serviço Social e Sociedade, São Paulo, Ano 22, n. esp., 2001.

GUERRA FILHO, Willis Santiago; CARNIO, Henrique Garbellini. Teoria política do direito: a expansão política do direito. São Paulo: Revista dos Tribunais, 2013.

HESSE, Konrad. A força normativa da Constituição. Porto Alegre: S. A. Fabris, 1991.

LAMANAUSKAS, Milton Fernando. A conciliação e mediação no sistema notarial e de registro como forma de ampliação do acesso à justiça. Revista de Direito Notarial, São Paulo v. 6, 2015.

LAMANAUSKAS, Milton Fernando. A conciliação e mediação no sistema notarial e de registro como forma de ampliação do acesso à Justiça. Revista de Direito Notarial, São Paulo, Ano 6, n. 6. p. 7-326, 2015.

MANCUSO, Rodolfo de Camargo. Acesso à justiça: condicionantes legítimas e ilegítimas. São Paulo: Ed. RT, 2011.

SILVA, Juvêncio Borges da. Acesso à Justiça como direito fundamental e sua efetivação 
jurisdicional. Revista de Direito Brasileira, Florianópolis, SC, v. 4, n. 3, p. 478-503, jan./abr. 2013.

SPENGLER, Fabiana Marion. Da jurisdição à mediação: por uma outra cultura no tratamento de conflitos. Ijui, SC: Unijui, 2010.

WATANABE, Kazuo. Acesso à justiça e sociedade moderna. In: GRINOVER, Ada Pellegrini;

DINAMARCO, Candido Ranger; WATANABE, Kazuo. (Coord.). Participação e processo. São Paulo: Ed. RT, 1988.

ZANFERDINI, Flávia de Almeida Montingelli. Desjudicializar conflitos: uma necessária releitura do acesso à Justiça. Revista Novos Estudos Jurídicos: NEJ, Itajaí, SC, v. 17, n. 2, maio/ ago. 2012.

Como citar: ZE/NKER, Anna Cristina e SILVA, Juvêncio Borges. Acesso à justiça pela atuação profilática do tabelião: A mediação extrajudicial como meio alternativo de dolução de conflitos. Scientia Iuris, Londrina, v. 22, n. 3, p. 88-110, nov. 2018. DOI: 10.5433/2178-8189.2018v22n3p88. ISSN: 2178-8189.

Recebido em: 27/09/2017.

Aprovado em: 13/07/2018. 